\title{
Micro-mechanical State at Tip of Environmentally Assisted Cracking in Nickel-based Alloy
}

\author{
Xue He, Li Yongqiang \\ Xi'an University of Science and Technology, Xi'an 710054, China
}

\begin{abstract}
Nickel-based alloys and austenitic stainless steels are widely used in the structures of primary circuit of nuclear power plants. Environmentally assisted cracking (EAC) of these materials is one of the most significant potential safety hazards in the primary circuit of nuclear power plants. Researches show that EAC in nickel-based alloy is a process of oxide film rupture and reform at the tip of EAC in the high temperature water environment of nuclear power plants. To understand the micro-mechanical state at the tip of EAC, the stress-strain in the oxide film and the base metal at the EAC tip was simulated and discussed using a commercial finite element analysis code, which provides a foundation to improve the quantitative predication accuracy of EAC growth rate of nickel-based alloys and austenitic stainless steels in the important structures of nuclear power plants.
\end{abstract}

Key words: nickel-based alloy; environmentally assisted cracking; oxide film; groove-type crack; finite element method (FEM)

With a good corrosion resistance and mechanical property in high temperature water environment, nickel-based alloys and austenitic stainless steels are widely used in the structures of primary circuit in nuclear power plants. But environmentally assisted cracking (EAC) of nickel-based alloys and austenitic stainless steels is an important issue in the safety operation of nuclear power plants ${ }^{[1,2]}$.

To understand the mechanism of EAC, the morphology at the EAC tip was investigated by transmission electron microscopy (TEM) in detail, which indicated that a dense oxide film is covered on the crack surface because of the electrochemical reaction at the EAC tip ${ }^{[3-6]}$. The further researches also showed that the oxide film at the EAC tip was a dense ceramic material $\mathrm{Cr}_{2} \mathrm{O}_{3}{ }^{[7,8]}$. The EAC growing in nickel-based alloys and austenitic stainless steels in high temperature water environment is a process of oxide film forming, rupture and reform at the EAC tip ${ }^{[9]}$.

While quantitative estimating of EAC growth rate in structure materials in the primary circuit of nuclear power plants is an important job, but it is also quite difficult to improve the estimated accuracy of the EAC growth rate in nickel-based alloys and austenitic stainless steels because of the complexity at the EAC tip. Therefore, experiments are still a general investigating approach in the EAC research field. However, it is a great challenge to predict the EAC growth rate of nickel-based alloys and austenitic stainless steels accurately in high temperature water environment of nuclear power plants due to expensive equipments, low experimental accuracy and long period ${ }^{[10-13]}$.

Researches on the theory and numerical simulation could effectively improve the prediction accuracy of the EAC growth rate and assist to analyze experiment data. The oxide film rupture theory at the EAC tip is widely adopted in the safety research field of nuclear power plants ${ }^{[14,15]}$. Based on this theory, the micro-mechanical state at the EAC tip and its effect on the EAC growth rate in nickel-based alloys were analyzed and discussed in the present paper.

\section{Theoretical Basis}

The oxide film rupture theory considers that the EAC process in nickel-based alloys and austenitic stainless steels in high temperature water environment can be divided into three

Received date: March 25, 2015

Foundation item: National Natural Science Foundation of China (51475362); Specialized Research Fund for the Doctoral Program of Higher Education (20136121110001)

Corresponding author: Xue He, Ph. D., Professor, School of Mechanical Engineering, Xi'an University of Science \& Technology, Xi'an 710054, P. R. China, Tel: 0086-29-85583846, E-mail: xue_he@hotmail.com 
periods: I-oxide film forming at the crack tip, II-oxide film aging and rupture at the crack tip with a high stress and strain, and III-anode metal separating at the crack tip ${ }^{[9,16]}$, which is shown in Fig.1.

Because the aging and rupture of the oxide film takes most of the time in EAC period, according to the Faraday's law, Ford and Andresen in GE deduced a formula to estimate the EAC growth rate of nickel-based alloys and austenitic stainless steels in high temperature water environment of nuclear power plants ${ }^{[9,17]}$ :

$$
\frac{\mathrm{d} a}{\mathrm{~d} t}=\frac{M}{z \rho F} \cdot \frac{i_{0}}{1-m} \cdot\left(\frac{t_{0}}{\varepsilon_{\mathrm{f}}}\right)^{m} \cdot\left(\frac{\mathrm{d} \varepsilon_{\mathrm{ct}}}{\mathrm{d} t}\right)^{m}
$$

where, $\mathrm{d} a / \mathrm{d} t$ is the EAC growth rate, $M$ and $\rho$ are the atomic mass and the density of metals, respectively, $F$ is Faraday's constant, $i_{0}$ is the bare surface oxidation current density, $z$ is the change in charge due to the oxidation process, $m$ is the exponent in the current decay curve, $\varepsilon_{\mathrm{f}}$ is the degradation strain of the oxide film, $t_{0}$ is the time before onset of the current decay, and $\mathrm{d} \varepsilon_{\mathrm{ct}} / \mathrm{d} t$ is the strain rate at the EAC tip.

Eq.(1) is the most widely used in prediction equation of the EAC growth rate in nickel-based alloys and austenitic stainless steels in high temperature water environment of nuclear power plants. To investigate the effect of the mechanical state on the EAC growth rate, a geometric model is sketched, as shown in Fig.2.

In Fig.2, the effect of the micro-mechanical state at the crack tip on EAC growth process can be illustrated as: Fig.2a denotes the surface oxide film forming at the crack tip of nickel-based alloys and austenitic stainless steels, which is

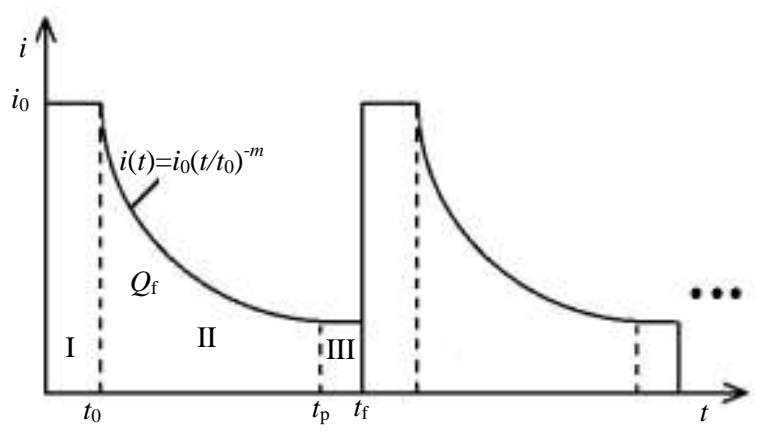

Fig.1 Schematic illustration of the oxidation current density transients at the crack tip

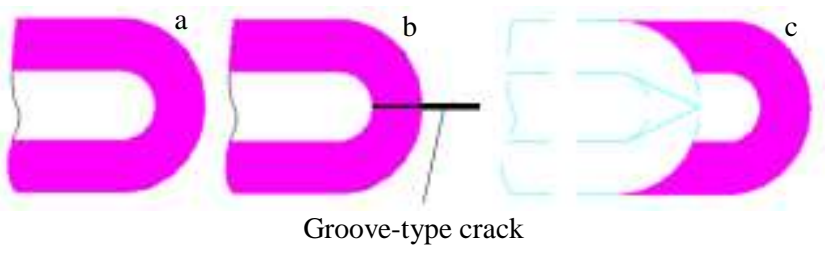

Fig.2 Sketch diagram of oxide film rupture and reform process: (a) oxide film form, (b) groove-type crack form and oxide film rupture, and (c) oxide film reform corresponding to period I in Fig.1; Fig.2b denotes a groovetype crack extends into the base metal and the surface oxide film aging and rupture at the crack tip because of an anodic electrochemical reaction at the crack tip, which is corresponding to period II in Fig.1; Fig.2c denotes the oxide film reform as the actual crack tip propagates, which is corresponding to periods III and I in Fig.1. This cycle occurs again and again, which leads to the damage of structures in nuclear power plants. Thus, the simulation and the study on micro-mechanical state of oxide film before and after rupture are important.

\section{Finite Element Model}

\subsection{Material model}

Ramberg-Osgood equation was used in the present simulation as the material mechanical relation for the nickelbased alloy at the EAC tip, which is written as follows:

$$
\frac{\varepsilon}{\varepsilon_{0}}=\frac{\sigma}{\sigma_{0}}+\alpha\left(\frac{\sigma}{\sigma_{0}}\right)^{n}
$$

where $\sigma$ is the stress, $\sigma_{0}$ is the yield strength of the material, $\varepsilon$ is the strain, $\varepsilon_{0}$ is the yield strain of the material, $\alpha$ is the dimensionless material constant, and $n$ is the strain hardening exponent of the material.

The material mechanical parameters of nickel-based alloy 600 are adopted as: $\sigma_{0}=436 \mathrm{MPa}, \alpha=1, n=5.29$ and $E$ is Young's modulus of the material and $E=190 \mathrm{GPa}$. The oxide film is a dense elastic material, whose mechanical parameters are set as $E=19 \mathrm{GPa}$, Poisson's ratio $v=0.3$, respectively ${ }^{[1]}$.

\subsection{Geometry model and mesh}

One inch compact tension (1T-CT) specimen was used in the present numerical calculation with the numerical experiment process according to the American Society for Testing and Materials Standard (ASTME399-90). The geometric shape and size of 1T-CT specimen are shown in Fig.3a. Constant concentrated loads were applied on the up and down pin holes, which kept the stress intensity factor $K_{\mathrm{I}}$ of 20 $\mathrm{MPa} \cdot \mathrm{m}^{1 / 2}$.

The thickness of the oxide film at the EAC tip was assumed to be $2 \mu \mathrm{m}$ in the present simulation ${ }^{[18,19]}$. The groove-type crack length was assumed as 1,2 and $3 \mu \mathrm{m}^{[10]}$. Three preset lines in the oxide film were used as the observation paths at the EAC tip, which are shown in Fig.3b. Where, path 1 is nearby the base metal, path 2 is nearby the oxide film surface and path 3 is along the cracking direction.

15421 CPE8 (8-node biquadratic plane strain quadrilateral) elements were adopted in the model. Because the stress concentration appeared nearby the boundary between the base metal and oxide film at the crack tip, the refined mesh was used in the crack tip region, which is shown in Fig.3c.

\section{Results and Discussion}

\subsection{Stress and strain at the crack tip}



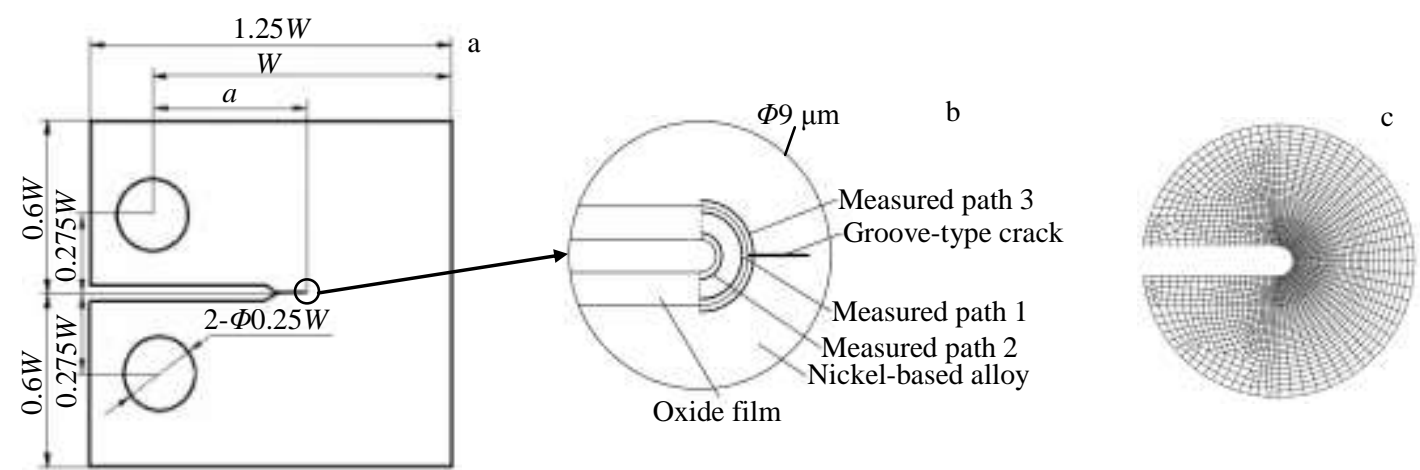

Fig.3 Finite element model: (a) geometric size of 1T-CT specimen ( $W=50 \mathrm{~mm}, a=0.5 W$ ), (b) measured paths at EAC tip, and (c) finite element mesh nearby the crack tip
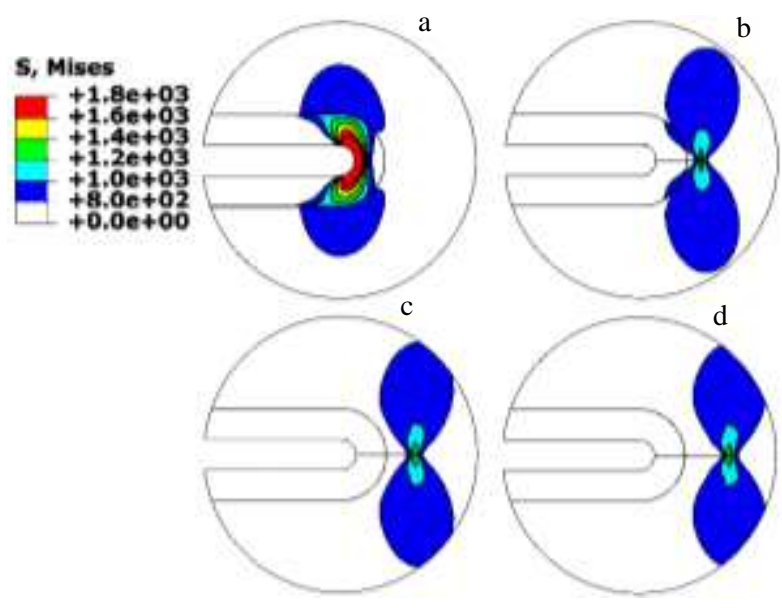

Fig.4 Stress nearby crack tip (MPa): (a) before oxide film rupture, (b) the groove-type crack length with $1 \mu \mathrm{m}$, (c) the groovetype crack length with $2 \mu \mathrm{m}$, and (d) the groove-type crack length with $3 \mu \mathrm{m}$

Stress distribution nearby the crack tip is shown in Fig.4. There are 7 contour lines representing the stresses, which are $0.0,800,1000,1200,1400,1600$ and $1800 \mathrm{MPa}$. The maximum stress at the crack tip exists in the oxide film before the oxide film rupture. The maximum stress at the crack tip moves from the oxide film to the groove-type crack tip in the base metal after the oxide film rupture. The longer the groove-type crack is, the farther the maximal stress advances. In the other hand, the groove-type crack length in a cycle is also associated with the EAC growth rate.

Strain distributions nearby the crack tip are shown in Fig.5. There are also 7 contour lines representing the strains, which are $12 \%, 10 \%, 8 \%, 6 \%, 4 \%, 2 \%$ and $0.0 \%$. The maximum strain is on the base metal nearby the boundary between the base metal and the oxide film before the oxide film rupture, and the maximum strain moves from the original crack tip to the groove-type crack tip after the oxide film rupture. The longer the groove-type crack is, the farther the maximal strain advances. Because the stress-strain at the crack tip is the main

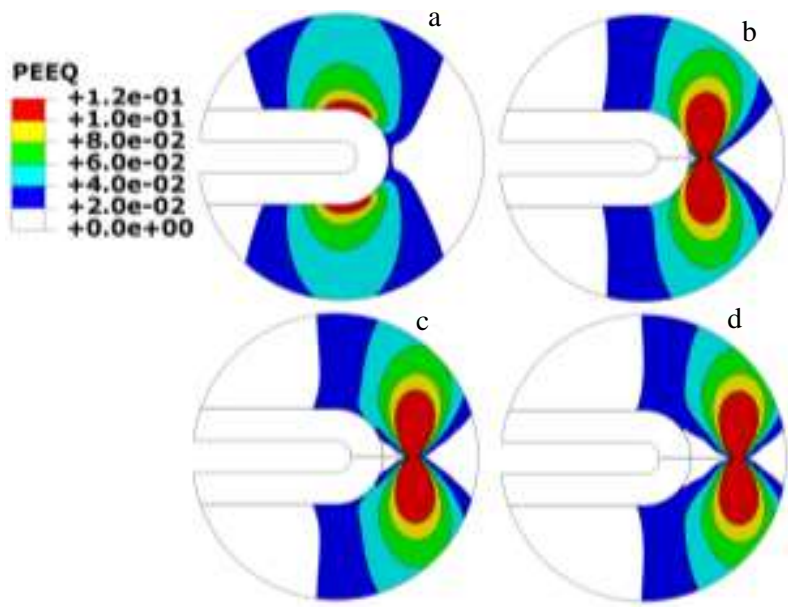

Fig.5 Strain nearby crack tip: (a) before oxide film rupture, (b) the groove-type crack length with $1 \mu \mathrm{m}$, (c) the groove-type crack length with $2 \mu \mathrm{m}$, and (d) the groove-type crack length with 3 $\mu \mathrm{m}$

factor to induce the oxide film rupture, the stress in the oxide film and the strain in the base metal at the crack tip before the oxide film rupture should be paid more attention to.

Stress distribution in oxide film at the crack tip is shown in Fig.6. It shows that the stress in the oxide film after the film rupture is much less than that before the film rupture, and the location of the maximum stress is also completely different by comparing the strains in Fig.6a and Fig.6b.

\subsection{Comparison of stress at the crack tip before and after oxide film rupture}

The stress along path 1 is shown in Fig.7. All minimal stresses in four situations before and after the oxide film rupture appear at $0^{\circ}$ direction, which is the crack propagating direction. The distribution morphology of stress along the path 1 before and after the oxide film ruptures is also basically similar. In addition, the gradient of stress is much bigger than others along path 1 when the groove-type crack length is $1 \mu \mathrm{m}$, which implies that stress gradient would be bigger when the groove-type crack begins to occur. 


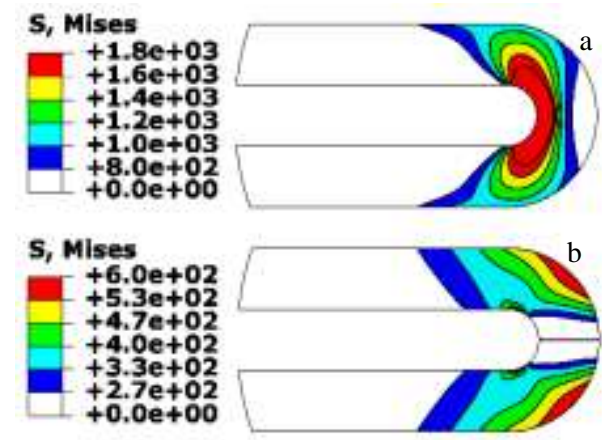

Fig.6 Stress in the oxide film (MPa): (a) before oxide film rupture and (b) after oxide film rupture

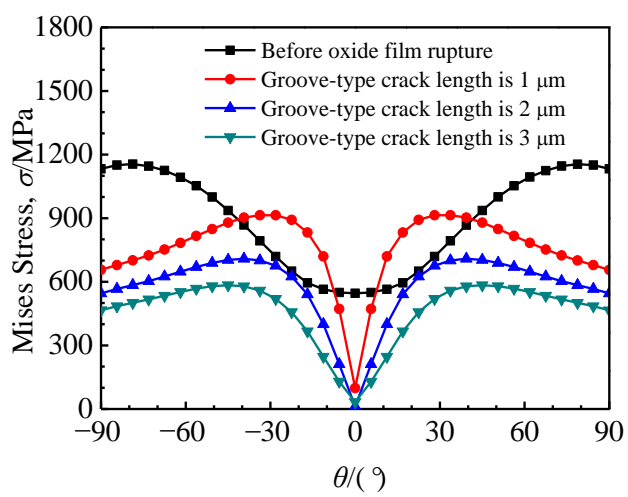

Fig.7 Mises stress along path 1

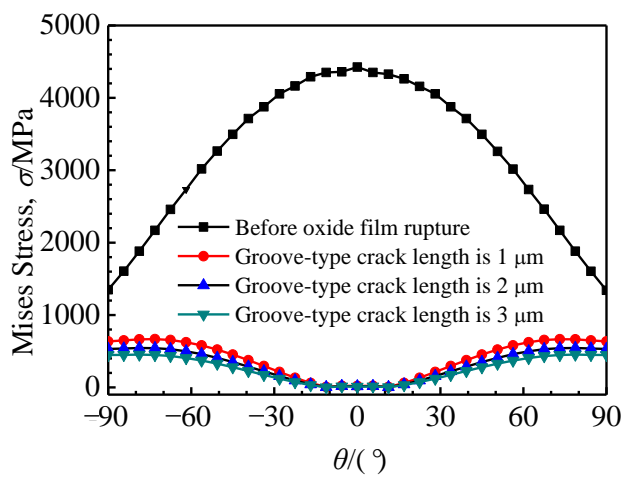

Fig.8 Mises stress along path 2

The stress along path 2 is shown in Fig.8. The maximal stress before the oxide film rupture appears at $0^{\circ}$ direction. In contrast, the minimal stress after the oxide film rupture also appears at $0^{\circ}$ direction. In addition, the stress before the oxide film rupture is much larger than the stress after the oxide film rupture along path 2. Comparing Fig.7 and Fig.8, it is shown that the surface stress before the oxide film rupture is larger than that in other location of the oxide film, which also implies that the in the film surface before the oxide film rupture may play a more important role in the process of the

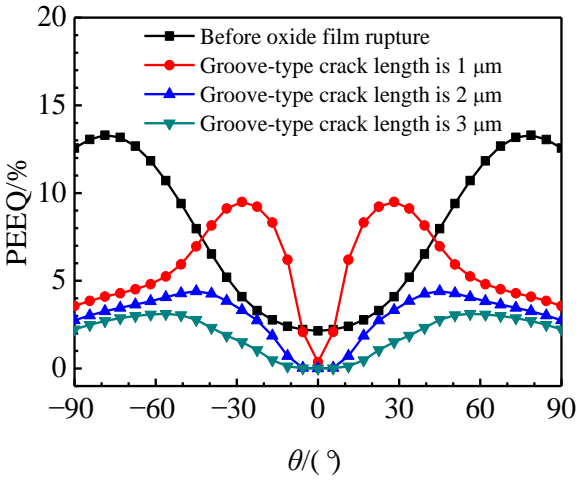

Fig.9 PEEQ (8-node biquadratic plane stain quadrilateral) along path 3

oxide film rupture.

The strain along path 3 is shown in Fig.9. Path 3 is a semicircular arc in the base metal next to the boundary between the base metal and the oxide film. All minimal strains in four situations before and after the oxide film rupture exist at $0^{\circ}$ direction, which is the crack propagating direction. The distribution rule of the strains along path 3 is basically similar to the distribution rule of the stresses along path 1 , which implies that there would not be a large error when taking the stress in the oxide film or the strain in the base metal as a basic mechanical parameter at the EAC tip.

\section{Conclusions}

1) Before the oxide film rupture, the maximum stress exists in the oxide film, and the maximum strain exists in the base metal, and both the maximum stress and the maximum strain move to the groove-type crack tip in the base metal.

2) After the oxide film rupture, the stress in the vicinity of oxide film and base metal decreases rapidly, which induce the oxide film to reform at the crack tip. The longer the groove-type crack propagates, the more the stress decreases at the primary crack tip. Furthermore, the groove-type crack length in a cycle also affects the EAC crack growth rate.

3) The stress in the oxide film and the strain in the base metal at the EAC tip affect the film rupture process, which should be paid sufficient attention to in the study of the EAC growth rate of nickel-based alloys and austenitic stainless steels in the important structures of nuclear power plants.

\section{References}

1 Xue H, Shoji T. Journal of Pressure Vessel Technology, Transactions of the ASME[J], 2007, 129: 254

2 Ruther W E, Soppet W K, Kassner T F. Corrosion[J], 1988, 44(11): 791

3 Elkebir O A, Szummer A. International Journal of Hydrogen Energy[J], 2002, 27: 793

$4 \mathrm{Lu} \mathrm{Y} \mathrm{H,} \mathrm{Peng} \mathrm{Q} \mathrm{T,} \mathrm{Sato} \mathrm{J} \mathrm{et} \mathrm{al.} \mathrm{Journal} \mathrm{of} \mathrm{Nuclear} \mathrm{Materials[J],}$ 2005, 347: 52 
5 Sennour M, Laghoutaris P, Guerre C et al. Journal of Nuclear Materials[J], 2009, 393: 254

6 Lozano-Perez S, Yamada T, Terachi T et al. Acta Materialia[J], 2009, 57: 5361

7 Zhang S H, Tan Y, Liang K X. Acta Metallurgica Sinica[J], 2011, 47(9): 1147 (in Chinese)

8 Tan Y, Zhang S H, Liang K X. Journal of Chinese Society for Corrosion and Protection[J], 2013, 33(6): 491 (in Chinese)

9 Xue H, Sato Y, Shoji T. Journal of Pressure Vessel Technology, Transactions of the ASME[J], 2009, 131: 61

10 Xue H, Xue X F, Tang W et al. Rare Metal Materials and Engineering [J], 2010, 40(8): 1188 (in Chinese)

11 Philippe M. Corrosion Mechanisms in Theory and Practice, $2 e d[\mathrm{M}]$. New York: Marcel Dekker Inc, 2002

$12 \mathrm{Li} \mathrm{H} \mathrm{L,} \mathrm{Feng} \mathrm{J} \mathrm{N,} \mathrm{Chu} \mathrm{W} \mathrm{Y.} \mathrm{Rare} \mathrm{Metal} \mathrm{Materials} \mathrm{and}$
Engineering[J], 2012, 41(S2): 247 (in Chinese)

13 Xue H, Li Z J, Lu Z P et al. Nuclear Engineering and Design[J], 2011, 24: 1371

14 Yang F Q, Xue H, Zhao L Y et al. Rare Metal Materials and Engineering[J], 2014, 43(2): 513 (in Chinese)

15 Shoji T, Lu Z P, Murakami H. Corr Sci[J], 2010, 52: 769

16 Andresen P L, Morra M M. Journal of Pressure Vessel Technology, Transactions of the ASME[J], 2007, 129: 488

17 Ford F P. Corrosion[J], 1996, 52: 375

18 Dimitris L, Pavlin E, Robertus T. Computer Methods in Applied Mechanics and Engineering[J], 2000, 183(1-2): 35

19 Zhu W Y, Qiao L J, Li J X et al. Hydrogen Embrittlement and Stress Corrosion Cracking[M]. Beijing: Science Press, 2013 (in Chinese)

\title{
镍基合金环境致裂过程中裂尖微观力学特性分析
}

\author{
薛 河, 李永强 \\ (西安科技大学, 陕西 西安 710054)
}

\begin{abstract}
摘 要: 核电站-回路压力容器、管道及蒸汽发生器等设备和结构中广泛采用镍基合金和奥氏体不锈钢, 而这些材料的环境致裂 (EAC) 却是核电结构的主要安全隐患之一。研究表明, 核电高温高压水环境中镍基合金的 EAC 是裂尖氧化膜破裂和再生成的一个过程。为了 深入了解镍基合金 EAC 裂纹扩展过程中裂尖的力学状况，从理论和数值模拟两方面分析研究了EAC 裂尖氧化膜和基体金属区域的应力 分布规律，为提高定量预测高温高压水环境中镍基合金 EAC 扩展速率精度奠定基础。
\end{abstract}

关键词：镍基合金；环境致裂；氧化膜；沟形裂纹；有限元法

作者简介: 薛 河, 男, 1961 年生, 博士, 教授 (博导), 西安科技大学机械工程学院, 陕西 西安 710054, 电话: 029-85583846, E-mail: xue_he@hotmail.com 